\title{
SOCIAL CAPITAL AND SUBSTANCE ABUSE TREATMENT AMONG LOW- INCOME PUERTO RICAN WOMEN
}

\author{
Humberto Reynoso Vallejo \\ humberto@bu.edu \\ Boston University School of Social Work \\ EUA
}

\section{RESUMEN}

La prevalencia del abuso de sustancias constituye un problema creciente entre las mujeres de bajos ingresos en Puerto Rico. El acceso a tratamiento puede jugar un rol importante en la remisión, sin embargo muy poco se sabe sobre su utilización. Además, se desconoce el papel mediador del capital social en la utilización de tratamientos para abuso de sustancias. Este estudio examina el papel relativo del capital social y otros factores en la obtención de tratamiento para abuso de sustancias entre mujeres de 18 a 35 años que viven en áreas urbanas de alto riesgo en San Juan, Puerto Rico.

Palabras clave: capital social, utilización de tratamientos para abuso de sustancias, mujeres puertorriqueñas.

\begin{abstract}
The prevalence of substance abuse constitutes an increasing problem among low-income urban women in Puerto Rico. Access to treatment may play an important role in remission, however, little is known about women's utilization. Further, the mediating role of social capital in substance abuse treatment utilization is unknown. This study examines the relative role of social capital and other factors in obtaining substance abuse treatment of women ages 18-35 living in high-risk urban areas of San Juan, Puerto Rico.
\end{abstract}

Key words: social capital, substance abuse treatment utilization, Puerto Rican women. 


\section{INTRODUCTION}

SUBSTANCE ABUSE AMONG PUERTO RICAN WOMEN. The prevalence of substance abuse appears to be increasing, especially among urban low-income young women in Puerto Rico (Ruiz \& Langrod 1997, Alegría et al. 2004). In the USA prevalence is increasing among Latinas in the United States from about 5\% in 2002 to $6 \%$ by 2008 (SAMHSA 2008). A previous study using NHSDA data reported that one in every five women in the general population fulfills the criteria for substance abuse or dependence in their lifetime (Kandel, Warner \& Kessler 2003). In a survey of 4,709 household residents aged 15 to 64 years old, conducted in Puerto Rico, $14.7 \%$ of the overall sample met the criteria for a lifetime substance disorder, despite concerns of significant underreporting (Colón, Robles \& Sahai 2001, 2002; Colón, Canino \& Sahai 2001). The Centers for Disease Control (CDC) reported an increasing number of HIV transmission due to intravenous drug use among Latinos in the US, especially among those of Puerto Rican origin (2007). In the Island, low education attainment, being unemployed, current alcohol use, and severe partner violence were found to be predictors of heavy drug use incidence among low-income urban women (Alegría et al., 2004). Another study of Puerto Rican women found that drug use is strongly associated with problem behaviors including arrests, incarceration and premature death; and negative social outcomes such as prostitution (Alegría et al., unpublished).

SOCIAL CAPITAL AND SUBSTANCE ABUSE. A number of studies in social epidemiology and public health used the concept of social capital in an effort to explain health outcomes among different population groups in society (Kawachi 1997, 1999; Kawachi, Kennedy \& Glass 1999; Berkman 2000; Szreter \& Woolcock 2002). Studies have focused on various topics including health and mental health (Cullen \& Whiteford 2001), mortality (Kawachi et al. 1997), income inequality and health (Godoy et al. 2007; Pearce \& Smith 2003; Coburn 2000; Wilkinson 1999; Kawachi et al. 1997; Kawachi, Kennedy \& Glass 1999), depression (Lin et al. 1999), stress (Steptoe \& Feldman 2001), child development (Keating 2000), crime and violence (Kawachi, Kennedy \& Wilkinson 1999), self-rated health (Kawachi, Kennedy \& Glass 1999), service use among homeless (Rosenheck et al. 2001), infectious diseases (Holtgrav \& Crosby 2003), and women's health-status (Kawachi et al. 
1999). In terms of substance use, however, social capital remains almost untouched with the exception of few studies. Two articles were published in 2000 (Lindstrom et al. 2000; Weitzman \& Kawachi 2000). Lindstrom and colleagues (2000) investigated whether psychosocial resources explain socioeconomic differences in smoking cessation and its maintenance among 11,837 adults, aged 45 to 65 , participating in a diet and cancer study between 1992 and 1994 in Sweden. They found that high levels of social participation were predictors of maintenance of smoking cessation. Initial odds ratio of 1.9 (1.4-2.5; 95\% CI) for men and 2.0 (1.4-2.7; 95\% CI) for women who stopped smoking were found for higher skilled employees when compared with unskilled manual workers. However, decreases in these odds ratios were found, when social participation was introduced into the model. Researchers concluded that high social participation was an important factor in the maintenance of smoking cessation and interpret their initial unadjusted findings to be a consequence of differing social network resources and social capital between the socioeconomic groups. On their part, Weitzman \& Kawachi (2000) investigated the protective effect of social capital on binge drinking on college campuses from a nationally representative survey of 17,592 enrolled students in 140 universities. They tested whether higher levels of social capital, operationalized as individuals' average time committed to volunteering aggregated to the campus level, on college campuses protected against individual risks of binge drinking. They found that individuals from campuses with higher than average levels of social capital had $26 \%$ lower individual risk for binge drinking than their peers of other universities. That is, social capital might play an important role in preventing binge drinking in college settings. A year later Cloud and Granfield (2001) explored qualitatively how the social capital accumulated and maintained during recovery by former alcohol and drug dependent persons aided in their recovery without treatment, using data collected from in-depth interviews with 46 former alcohol and drug dependent persons in the context of "natural recovery." More specifically, they explored how the person's relations within their lives and the actual virtual resources available through their social capital aided their "natural recovery" from drug-use related problems. Natural recovery strategies were clustered into three areas: (1) alternative activities; (2) significant 
relationships with non-users; and, (3) avoidance of relationships and situations conducive to drug use. Elements of recovery capital were identified as social capital, physical capital, and human capital. The elements include personal attributes and environmental or contextual conditions that help enable recovery. Considering the limitation of their very homogenous sample (White, educated, middle-class) and the study design (46 qualitative interviews), they found that the more social and personal resources people had the greater the chances of overcoming substance dependency. Their findings serve two purposes: (1) confirm the importance of engaging in alternative activities, relying upon relationships with family and friends, avoiding drug users and drug environments; and, (2) introduction of the concept of "recovery capital" to capture the personal and social resources that allowed substance abusers to employ these strategies adds to the theoretical discourse of substance abuse recovery. In 2002, Lovell analyzed forms of capital, social network characteristics and other contextual factors influencing risky injection behavior among injection drug users in Marseilles, France (Lovell 2002). Quantitative and qualitative data were collected among intravenous drug users where sterile injection equipment has been legal and government sponsored. In a multilevel analysis, she found that location in the densest part of a large, interconnected network of intravenous drug users greatly increased the likelihood of risky injection practices. Illicit use of prescribed medication, such as methadone and high dose brupenorphine, and unprotected sex were found to be the strongest individual-level characteristics. Her qualitative component suggests that risky injection may be linked to a lack of resources to buy clean needles, and not simply to inadequate access to sterile injection equipment. Lovell concluded with a call for a better understanding of social conditions as they relate to risk behaviors among drug injectors to minimize risks, and increase public health initiatives at the community-level. Two articles were written in 2003 (Lindstrom 2003; Kandel et al. 2003). Lindstrom (2003) investigated the impact of social participation, trust and what he called the "miniaturization of community" (high social participation and low trust) on daily and intermittent smoking in a public health survey of 13,715 persons in Scania, Sweden. He developed four basic categories: (1) high social participation high trust (high social capital); (2) high social participation /low trust 
(miniaturization of community); (3) low social participation/high trust (traditionalism); and, (4) low social participation/low trust (low social capital). Daily smoking was negatively associated with both social participation and trust, while intermittent smoking was positively associated with social participation and negatively associated with trust (the miniaturization of community). He concluded that low social capital was associated with daily smoking, while the miniaturization of community was significantly associated with intermittent smoking. Results have direct implications for smoking prevention strategies, recommending that restrictions and prohibitions of smoking in public should be extended. The Psychiatric Institute's Research Department on Epidemiology of Substance Abuse at Columbia University published on their website the research conducted by Kandel et al (2003), aiming to identify risk and protective factors that can either promote or prevent the progression of daily smoking, nicotine dependence and substance abuse among youths. It also investigated ethnic and gender differences in these factors, and the characteristics of more effective school-based smoking and substance use prevention programs. They reported that predictors of alcohol, cigarettes, marijuana and cocaine dependence are mostly the same. For every drug class, extensive use of the drug was highly correlated to dependence on that drug. There are also effects of extensive use across drug classes. Extensive marijuana use increased the risk of dependence on alcohol and cigarettes; extensive alcohol use increased the risk of cigarette and marijuana dependence. By contrast, dependence on cocaine appeared not to be influenced by extensive use of any other substances. Sensation seeking was a strong correlate of dependence on all drugs, except cocaine, while community social capital decreases the likelihood of dependence on all four classes of drugs (Kandel et al 2003). In sum, research reported that higher levels of social capital are positively associated with reduction of substance use or abuse, and lessening the risks related to drug use and dependence. However, none of the existing studies linking social capital to substance abuse have considered the role of social capital in obtaining substance abuse treatment. These studies used different dependent variables and different measures of social capital at either the individual or ecological levels. In addition, all suggest that social capital has a protective effect on drug use outcomes but they say little 
about the mechanisms. Considering that higher levels of social capital have a favorable impact on substance use/abuse and its consequences, it is important to explore the role of social capital in obtaining substance abuse treatment among Puerto Rican women.

SUBSTANCE ABUSE AND TREATMENT FOR PUERTO RICAN WOMEN. There are no estimates on the number of people from Latino subgroups in need of treatment, however, we can infer, based on the data proportioned by the NHSDA (2008) and on the premise of the expected correlation between substance abuse or dependence and need of treatment, that the number of people is significant. A preliminary report from a national survey based on answers by treatment program directors, Latinos account for $9.8 \%$ of the total population in treatment, $7 \%$ in a hospital setting, $10.1 \%$ in residential programs and $5.7 \%$ in a combination (Mardsen 1999: 15). Latinos are over-represented in alcohol abuse research, including drinking-driving programs, but not in treatment programs (Weisner \& Schmidt 2001: 114). This may suggest either less use of treatment programs, lack of adequate attention, or difficulties in accessing this population on the part of researchers. Lasser and colleagues (2002) reported that ethnic/racial minorities receive about half as much outpatient mental health care as whites. In the history of substance abuse treatment in the US, there has been no explicit emphasis on ethnic/racial groups until the last decade with the introduction of culturally competent/sensitive practices. From the thirties to the sixties, the treatment was physician based, moving towards a more socially-business oriented approach during the 80's with the Health Maintenance Organizations (HMO's) and the increasing competition. In Puerto Rico, the introduction of managed care and privatization practices had minimal impact on the use of substance abuse treatment, increasing the use among well-off while maintaining the same level of use for poor people (Alegría et al. 2001). The question remaining to be answered is how to improve access for low-income urban persons (Alegría et al. 2001, 2002; Mulia 2002). Finally, other recent research shows that women and men differ in substance abuse etiology, progression, and access to treatment for substance abuse (Ashley, Marsden \& Brady 2003). A study conducted in Puerto Rico found that males and females use mental health services in nearly equal 
proportions (Albizu-García et al. 2001). The delivery of substance abuse treatment has to be specifically designed for women in order to meet their distinctive needs and to reduce barriers to receive and remain in treatment. Puerto Ricans have a high prevalence of drug use and less access treatment compared to other groups in the US (Mardsen 1999; Weisner $\&$ Schmidt 2001). Studying the relative role of social capital in obtaining substance abuse treatment for low-income Puerto Rican women may assist to better understand the pathways of recovery as well as to inform social policies intended to eradicate or ameliorate the negative effects of substance abuse.

\section{THEORETHICAL FRAMEWORKS}

WOMEN AND SUBSTANCE ABUSE._Alegría et al (2002) have proposed a framework that combines different models to understand Latino female drug users, including the stressvulnerability model (Pearlin et al. 1981), family interactional model (Brook et al. 1988), and social learning theory (Akers et al. 1979; Bandura 1977). They argued that these three models complement and inform each other in explaining the etiology of substance abuse. The stress-vulnerability model posits that the more increased levels of stress (i.e., caregiver burden) or stressful life experiences (i.e., divorce, death in family) the greater the chance that women use or abuse drugs. This is especially true for those women who do not have factors that foster resilience such as institutional resources or social support networks. Furthermore, sources of stress may come from at least three different domains: interpersonal, neighborhood, and institutional. For instance, the interpersonal factors that can contribute or buffer from increased risk for drug use are: marital/partner satisfaction, family values and attitudes, and intrafamilial harmony or discord. Neighborhood factors that affect drug use include but are not limited to: type of setting (urban or rural), neighborhood income, perceived acceptance or disapproval of drug use, and physical environment (i.e. crime, unemployment). Institutional factors refer for example to the availability of health facilities and treatment, dependence or independence from public system, any history of incarceration, satisfaction with drug service providers, and perceived helpfulness of services. The family interactional model explains that support from the family and positive family interaction can be factors that contribute to a woman's resiliency 
from the risks of drug use (Brook et al. 1988, 1990). There is some research pointing to lack of support from family and friends as being a characteristic of female drug abusers (Nyamathi \& Vásquez 1988). Family dynamics can impact not only drug use but also helpseeking behaviors that may lead to treatment. Social learning theory emphasizes the importance of observing and modeling the behaviors, attitudes, and emotional reactions of others (Bandura 1977). This theory explains human behavior in terms of continuous reciprocal interaction between cognitive, behavioral, and environmental influences. It has been applied extensively to the understanding of aggression (Bandura 1977) and psychological disorders, particularly in the context of behavior modification (Bandura 1969). With respect to substance abuse, it is hypothesized that women learn problem behaviors (i.e. criminal activity) through the same vehicles of social influence that they learn conventional or prosocial behaviors. For instance, if a spouse is a drug user, women may be in higher risk of using. Women were approximately five times more likely to use drugs or be heavy alcohol consumers if their partners were also users (Bresnahan et al. 1992). Figure 1 presents a conceptual framework that encompasses the four domainspersonal, interpersonal, neighborhood, and institutional-- which are relevant in explaining drug use and treatment participation for the sample of Puerto Rican women examined in this research. I added a fifth domain with the purpose of capturing the broader social/political environment dimension, by including the particular social history of Puerto Rico and the political-economy sphere (Singer 1999). 
Figure 1: Conceptual Framework of Drug Use and Consequences of Latino Women (adapted from Alegría et al., 2002)

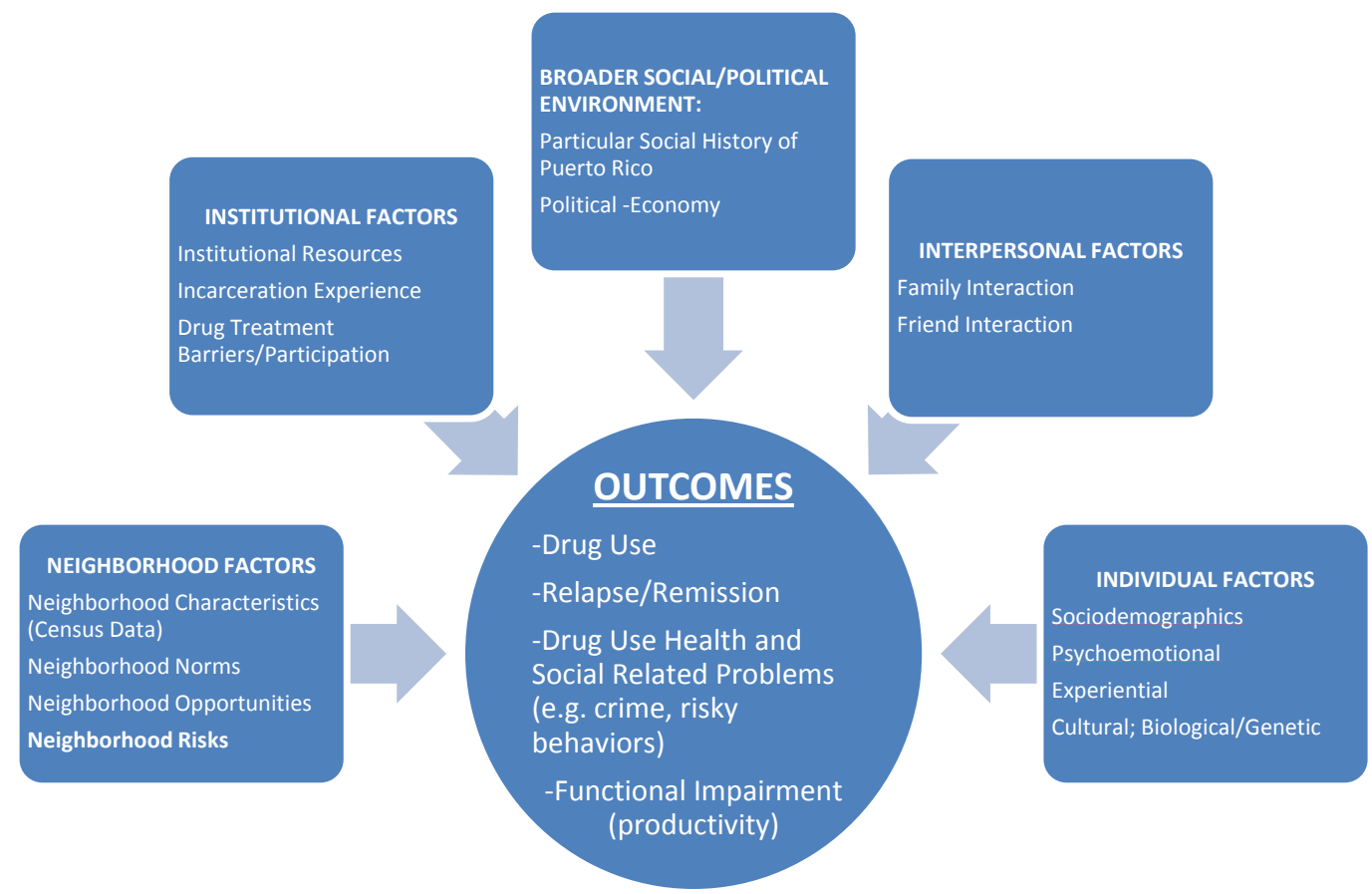

Some methodological and conceptual challenges in substance abuse among Latinas include the consideration of gender differences, the absence of a clear and comprehensive picture of the substance abuse patterns within and across subgroups (Amaro \& De la Torre 2002), the fact that most studies rely on self-reports (Morral et al. 2000), which, for Latinas, may result in an underreporting due to the threat of losing custody of their children (Alegría et al. 2002). Moreover, most surveys have not been developed specifically for women rather for men. Also, pointed to the gap in our understanding of the developmental trajectory of drug abuse and treatment as directly linked to the use of cross-sectional designs rather than longitudinal. Current conceptual models use a deficit approach that focus on the woman's loss of control or maladaptive behavior as the cause of their drug use. Social and economic factors influence risk behavior and the health of drug users represented by differential access to available resources, social welfare systems, and creating marginalization. Ethnic/racial groups experience a disproportionately higher level of adverse social factors 
that affect negatively their health. Therefore, public health interventions aimed at improving the health of drug users must address the social factors that accompany and exacerbate the consequences of illicit drug use. (Galea \& Vlahov 2002).

SOCIAL CAPITAL. Social capital may be defined as the inherent resources in social relations that facilitate collective action. Social capital resources include trust, norms of reciprocity, and networks. Coleman (1988) described social capital as a product of individuals' rational action in controlling resources. It is represented by norms of obligation, expectation, and trustworthiness derived from individuals' social ties. Loury (1992, quoted by Woolcock 1998: 189) described social capital as the social relationships among persons that promote the "...acquisition of skills and traits valued (in the) marketplace... an asset which may be significant as financial bequest in accounting for the maintenance of inequality in our society". Robert Putnam states that social capital refers to the connections among individuals that create social networks and the norms of reciprocity and trustworthiness (2000: 19). Social capital refers to those features of social relationships--such as levels of interpersonal trust and norms of reciprocity and mutual aid--that facilitate collective action for mutual benefit (Kawachi 1999). The construction of social capital remains controversial and has taken several distinct directions. Szreter \& Woolckock (2002) divided the approaches into three forms: social support, inequality, and, political economy. Whereas Godoy et al. (2007) and Pearce \& Smith (2003) used two: social-capital and neomaterialist. The social-capital approach states that a decline in social capital creates distrust, shame and negative behaviors leading to health problems (Godoy et al. 2007). The neomaterialist approach argues that health reflects income, human capital, wealth, and access to health services (Godoy et al. 2007; Pearce \& Smith 2003). Therefore, health problems may be related to individual-level variables and not to relational aspects of community life. For the purposes of this research, the social support approach is used instead of the neomaterialist, inequality or political economy approach. To distinguish social capital as a concept from social capital as an approach, the latter will be identified as social supports using Berkman's term (2000). Although measuring social capital may be difficult (The 
World Bank Group 2002) most authors using the social-capital approach concur that representative features of social support among people include trust between people, reciprocity, and group membership (Kawachi, Kennedy \& Glass 1999).

SOCIAL SUPPORT APPROACH. This approach conceives of social capital as the result of an individual's social relationships in a given community. The relationships outcome is measured by the interpersonal trust, the norms of reciprocity, and membership of civic organizations. The concept is been formulated as "social cohesion" (Kawachi, Kennedy \& Glass 1997; Berkman 2000), "social support" (Berkman 2000), "social integration" (Berkman \& Glass 2000) or "civil society" (Baum 1997). The conceptual model used in this study is derived from the theory developed by Kawachi \& Berkman (2000) that examines the mechanisms by which social capital affects an individual's health. Their theory is that social capital may affect health through three different pathways (1) by influencing health-related behaviors; (2) by influencing access to services and amenities; and (3) by affecting psychosocial processes (2000: 184). The mechanism by which individual level social capital may influence access to services and amenities is used conceptually in trying to demonstrate the role of social capital in obtaining substance abuse treatment. The other two mechanisms, health-related behaviors and psychosocial processes, account for epidemiological outcomes and serve as a frame of reference for this study. The expectation is that higher levels of social capital will correspond to more substance abuse treatment utilization.

SUBSTANCE ABUSE TREATMENT. Treatment provided many beneficial outcomes, for instance, a chapter reviewing the existing research (McLellan \& McKay 1998) found that treatment outcomes include the sustained reduction of the severity of drug abuse, the sustained increase in social function, and the sustained reduction of public health threats. Sustained increase of social function outcome will be used in the present study to hypothesize that women who received treatment would have higher levels of functioning, which may be reflected in the development of a more supportive environment that may 
include the components of social capital (trust, reciprocity, and membership). It is also expected that treatment participants who received or developed support from relationships non-associated to drugs will be in remission. Higher levels of social capital have a positive effect in the health (Kawachi, Kennedy \& Glass 1999; Kawachi \& Berkman 2001), that is, individuals with higher levels are healthier than individuals with lower levels (Bolin et al. 2003). However, there are neither studies researching the role of social capital in obtaining substance abuse treatment, nor any associating treatment with changes in social capital. Based on the findings of the social capital and substance abuse studies, it seems reasonable to suggest that social capital may influence treatment utilization, and that people having treatment will show better outcomes including higher levels of social capital.

\section{METHODS}

Data use in this research is the Inner City Latina Drug Use Study (ICLDUS) collected from low-income women in metropolitan urban areas of San Juan, Puerto Rico. Two samples of women 18 to 35 years of age were included in the ICLDUS study. The first group is a sample of women using opiates or crack/cocaine from copping areas (copping area sample). The second group is a sample of women within the radius of half a mile of the copping area and within the same neighborhoods (community sample). The ICLDUS survey instrument was administered between the years 1996 and 2000. Baseline data, Wave I, was collected between 1996 and 1997 from a sample of 718 women, with a response rate of $81.4 \%$. The first follow up, Wave II, was conducted with a total of 696 women between July 1998 and June of 1999. A total of 681 women were re-interviewed for the second follow up, Wave III, during July of 1999 through November of 2000. Respondents who remained in the study for the three waves as compared to those who dropped out from Wave I to Wave II $(n=54)$ or from Wave II to Wave III $(n=29)$ were more likely to be from the copping area sample, older (30-38 years of age), returned migrants to the island, self-reported drug users, HIV positive, and women practicing prostitution (Alegría, et al. unpublished). Participant women were drawn from 7 municipalities in the San Juan metropolitan area, including San Juan, Carolina, Trujillo Alto, Bayamón, Caguas, Guaynabo and Cataño. 
COPPING AREA SAMPLE. At baseline, a sample of 275 female drug users were selected from drug purchasers or users at drug copping areas in the inner city low-income communities of the San Juan extended area (775 square miles). The number of participants who were successfully re-contacted for interviews during the study includes 235 by Wave II, and 229 by Wave III. Drug copping areas are specific places within the community where drugs are purchased and/or used, such as crack houses or shooting galleries. The ICDLUS identified these copping areas using the sampling design of Reyes and colleagues (1993) to monitor risk behaviors among drug users with HIV. Female trained outreach workers approached potential females in the randomly selected copping area sample to explain the objectives of the study, screen for study eligibility and invite the women to participate. A total of 316 women were contacted in the copping areas. Of these women, 3 refused to participate and 38 were ineligible because of the age criteria, for a response rate of $98.9 \%$ in the copping area baseline sample (Alegría et al. unpublished). In this study, only the copping area sample is used for the analysis instead of merging the copping and community samples. After conducting preliminary analysis, the samples were found to have significant differences in many important ways. Women recruited from the copping areas were more likely to be drug users, to receive treatment during the study, and to remain during all three waves, in comparison to those from the community sample. The patterns of substance abuse both in the past and during the study differ between both groups, where participants from the copping area had more treatment episodes ever and during the study. In terms of active drug use, by Wave I only 72 participant women from the community sample, representing $16.2 \%$, met the criteria for drug use, in comparison to $100 \%$ of participant women (275) from the copping area sample. The criteria for drug use include self-report drug use, a toxicological test result and a diagnosis of drug abuse. Toxicological test results were based on hair and urine sample collected during the interview. Diagnosis of drug abuse and alcohol dependence was given to participants who met DSM IV criteria. Table 1 compares drug-using women from the copping area sample with the community sample, showing important differences. Response rates of the copping area sample in Wave I was $98.9 \%$; Wave II $90.3 \%$; and, $93.1 \%$ in Wave III. A notable number of participants died 
during the study (18 women between July 1998 and June 1999; and 14 women between July 1999 and October 2000), others were not localized (20 in Wave II, and 11 in Wave III), and a small proportion refused to continue their participation in the study, 2 and 1 respectively. A total of 235 participants were successfully interviewed by Wave II (275-18 participants who died-20 not localized-2 who refuse=235). By Wave III, out of the 275 original participants at baseline, a total of 229 women were interviewed (275-18 who died14 who died -13 not localized -1 refusal=229).

Table 1: Differences among Drug Users from both Samples Wave I

\begin{tabular}{|lllll|}
\hline & \multicolumn{2}{l}{ Copping Area Sample } & \multicolumn{2}{l}{ Community Sample } \\
& $\mathrm{n}=275$ & & \multicolumn{2}{c|}{$\mathrm{N}=72(16.2 \%$ of total) } \\
\hline & Mean & SD & Mean & SD \\
\hline Age** & 28.72 & 4.25 & 26.97 & 4.73 \\
\hline Children Living With You*** & .81 & 1.13 & 1.75 & 1.17 \\
\hline Employment Status* & 2.33 & .63 & 2.16 & .67 \\
\hline Part-time Job** & 1.02 & .15 & 1.10 & .30 \\
\hline Head of Household*** & 1.47 & .62 & 1.18 & .38 \\
\hline $\begin{array}{l}\text { Total Income, Monthly } \\
\text { Labor* Sum Labor }\end{array}$ & 314.8 & 369.12 & 438.24 & 286.36 \\
\hline Total Expenses in Drugs* & & & & \\
\hline Prostitution Practice*** & 297.11 & 335.68 & 124.55 & 287.27 \\
\hline Cocaine Age of Onset*** & .46 & .49 & .04 & .20 \\
\hline Heroine Age of Onset*** & 1.29 & .87 & .38 & .77 \\
\hline Cocaine/Opiates Frequency of Use*** & 1.01 & .93 & .25 & .66 \\
\hline Cocaine Frequency of Use*** & 1.24 & .70 & 2.44 & 1.55 \\
\hline Age at First Drug Use*** & 1.47 & .97 & 2.61 & 1.51 \\
\hline \hline
\end{tabular}

Symbols for Chi-Square Test level of significance used for Characteristics are:

$*$ P-value $<0.05$;

$* *$ P-value $<0.01 ; * * * \mathrm{P}$-value $<.001$.

Demographic characteristics of the copping area participant women are represented in Table 2. The majority of them were single during all 3 waves, living with a partner, 
separated, unemployed seeking for work, received social services lived in the neighborhood a little more than 14 years, and born on the Island.

DEPENDENT VARIABLES. Several dichotomous dependent variables are used to measure treatment and modality including:

a) Detox: defined as treatment aiming at avoiding physical withdrawal; b) Methadone maintenance: consisted of any visit to a clinic dispensing the drug as a replacement for opiates; c) Residential therapeutic community: provides intensive group intervention to prevent using drugs; d) Prison: any treatment received while incarcerated; e) Ambulatory non-methadone: outpatient treatment; and e) Other. Considering that participants received treatment before the study and/or during the study, two dependent variables were created: treatment and modality prior to the study (coded as $0=$ no treatment, and 32 possible combinations of treatment types). Also, a variable for treatment received during the study was created. In terms of social capital, four dependent variables, subscales' scores of social capital in Wave III, were created using factor analysis of the social support/networks, physical environment and religion instruments of the ICLDUS. Social capital subscales are continuous variables except for the item from the religiosity instrument used to measure social participation. The purpose of developing these dependent variables is to measure changes in social capital for participants who either received or did not receive treatment during the study. 
Table 2: Demographic Breakdown of Copping Area Sample by Data Wave

\begin{tabular}{|c|c|c|c|}
\hline Participant Demographics & $\begin{array}{l}\text { Wave I } \\
\text { (May } 97 \text { to Jun } \\
\text { 1998) } \\
\text { Frequencies }\end{array}$ & $\begin{array}{l}\text { Wave II } \\
\text { (Jul } 98 \text { to Jun 99) } \\
\text { Frequencies }\end{array}$ & $\begin{array}{l}\text { Wave III } \\
(\text { Jul } 99 \text {-Oct } \\
2000) \\
\text { Frequencies }\end{array}$ \\
\hline $\begin{array}{l}\text { Mean Age } \\
\text { Marital Status: }\end{array}$ & 28.72 & 30.03 & 30.88 \\
\hline Married & $11(4.0 \%)$ & $9(3.8 \%)$ & $7(3.1 \%)$ \\
\hline Single & $125(45.5 \%)$ & $105(44.7 \%)$ & $123(53.9 \%)$ \\
\hline Living with Partner & $83(30.2 \%)$ & $79(33.6 \%)$ & $69(30.3 \%)$ \\
\hline Separated & $33(12.0 \%)$ & $27(11.5 \%)$ & $16(7.0 \%)$ \\
\hline Divorced & $14(5.1 \%)$ & $12(5.1 \%)$ & $6(2.6 \%)$ \\
\hline Widow & $7(2.5 \%)$ & $3(1.3 \%)$ & $7(3.1 \%)$ \\
\hline $\begin{array}{l}\text { Years of Education } \\
\text { Employment Status: }\end{array}$ & 9.81 & 9.58 & 9.71 \\
\hline Full-Time & $8(2.9 \%)$ & $9(3.8 \%)$ & $16(7.0 \%)$ \\
\hline Part-Time & $7(2.5 \%)$ & $11(4.7 \%)$ & $8(3.5 \%)$ \\
\hline Unempl. Seeking for Work & $113(41.1 \%)$ & $86(36.6 \%)$ & $45(19.7 \%)$ \\
\hline Unempl. Not-Seeking for Work & $59(21.5 \%)$ & $76(32.3 \%)$ & $58(25.4 \%)$ \\
\hline No. of People in Family Composition & 3.01 & 2.96 & 2.89 \\
\hline Children Living with Participant & $40.4 \%$ & $40.0 \%$ & $34.6 \%$ \\
\hline Monthly Income & 314.86 & 287.44 & 340.27 \\
\hline Received Social Services & $163(59.3 \%)$ & $151(64.3 \%)$ & $137(60.1 \%)$ \\
\hline Years Living in the Neighborhood & 14.10 & 14.33 & 14.17 \\
\hline Born in Puerto Rico & $88.6 \%$ & $89.4 \%$ & $90.4 \%$ \\
\hline Born in the USA & $10.2 \%$ & $8.9 \%$ & $8.9 \%$ \\
\hline
\end{tabular}

INDEPENDENT VARIABLES. In order to determine the sample to be studied in this research, a chi-square analysis between the copping area and community samples was performed finding significantly difference in age, children living with you, employment status, parttime job, monthly income, head of household, money spent in drugs, prostitution practice, heroine age of onset, cocaine age of onset, frequency of cocaine and opiates use, and age at first drug use. To analyze the demographic breakdown of the copping area sample, several 
variables were utilized including marital and employment status, received social services, and place of birth. Variables include age, years of education, number of people in family composition, children living with participant, monthly income, and years living in the neighborhood. A number of covariates were considered in the analyses of treatment use and social capital scales in Waves I and III, based on theory and prior analyses. A large number of covariates were included in the initial model and, using stepwise ordinary least square with forward selection, only the ones found to be statistically significant at the $p=<.05$ were kept. In the case of treatment utilization, the effect of social capital was tested after controlling for other determinants of treatment, with the purpose of finding the independent effect of social capital in treatment use. In the case of social capital, the independent effect of treatment utilization on social capital by Wave III was tested, controlling for other predictors.

QUALITATIVE INTERVIEWS. Due to the particularities of substance abuse treatment arrangements in Puerto Rico, and to complement the quantitative analysis of this study, a qualitative component was added. Interviews were conducted in 2004 with the principal investigator of the ICLDUS (M. Alegría), and from the Center on Addiction Studies of the Universidad Central del Caribe School of Medicine in Puerto Rico, H. Colón and E. Quiñones.

ANALYSIS AND HYPOTHESIS TESTING. The first question is: Does social capital predict participating in treatment programs? Hypothesis was that higher levels of the social capital predict participation in one or more treatment programs (Vera et al. 1998; Nyamathi et al. 2000, and Pescosolido et al. 1998). A bivariate analysis was used to determine the correlates of obtaining treatment either before or during the study, and only covariates with significant bivariate relation $(\mathrm{p}=<.05)$ to the dependent variable "received treatment" were included. Once the covariates were identified through bivariate analysis, a set of more parsimonious covariates in multivariate logistic regression with forward entry conditions were used. Then, tested social capital measures and covariates found to be not significant in 
the logistic regression were removed from the model with the exception of the social capital measures. The second question: Does participation in drug treatment programs increase social capital?, derived the hypothesis that: Women who participated in a drug treatment program will experience an increase in social capital (McLellan \& McKay 1998; Kawachi, Kennedy \& Glass 1999; Kawachi \& Berkman 2001; Bolin et al. 2003). A linear regression was run to determine predictors of social capital by Wave III, controlling for other factors such as employment and demographics. Social capital in Wave III appeared as a dependent variable in the model, and social capital in Wave I constituted one of the independent variables. A t-test was conducted to determine the mean differences in social capital scales between Waves I and III. Supplemental analysis on social capital scores between Wave I and Wave III were performed by regressing various measures. Third question: Is there a significant difference among treatment modalities in predicting social capital change? The hypothesis was that residential therapeutic community treatment will result in the most significant increase in social capital (Reiff-Ross \& Adams 1977-78; McCarty et al. 2000; McLellan et al. 1997). A t-test was performed to determine the contribution to changes in social capital between the group that received at least one residential therapeutic community and the group that received other than residential type of treatment.

\section{FINDINGS}

Findings supported the rejection of the three proposed hypotheses in this study: 1) no significant association was found between levels of social capital and getting treatment; 2) women who participated in a drug treatment did not experience an increase in social capital; and 3) women who had at least one episode of residential therapeutic community treatment did not increase their levels of social capital. Table 3 shows descriptives for people who remained during all 3 waves of the study compared to those who were not available in subsequent waves either because they died, opted not to continue in the study, or were not localized. There was no significant difference among the participants who remained in all waves from those who left the study, except in the proportion of HIV positive cases, age, lower educational levels, out of labor force, had a sexually transmitted disease, and prostitution practices. According to Colón, in a study conducted by him (not 
yet published), on a combined sample of men and women of approximately 1,200 drug users, the mortality rate was 4.4 deaths for each 100 person per year, and higher for drug using women. Women who received any type of treatment during the study $(21.2 \%)$ is significantly lower, compared $73.1 \%$ who received treatment before the study.

The number of participants who received treatment during the study was $52(21.2 \%)$, with 48 by Wave II and 18 by Wave III. Because 7 participants received treatment during both waves, the total number of women who received treatment during the study is 52 $(48-7+11=52)$. The most frequent type of treatment before the study was residential therapeutic community with $18.2 \%$ of the total sample, followed by a combination of detox and residential therapeutic community with $14.5 \%$, only detox type with $9.8 \%$, and a combination of detox, residential therapeutic. 
Table 3: Characteristic of Copping Area respondents who remained in the study and those who left the study (died, not wanted to continue, and not localized) by Wave

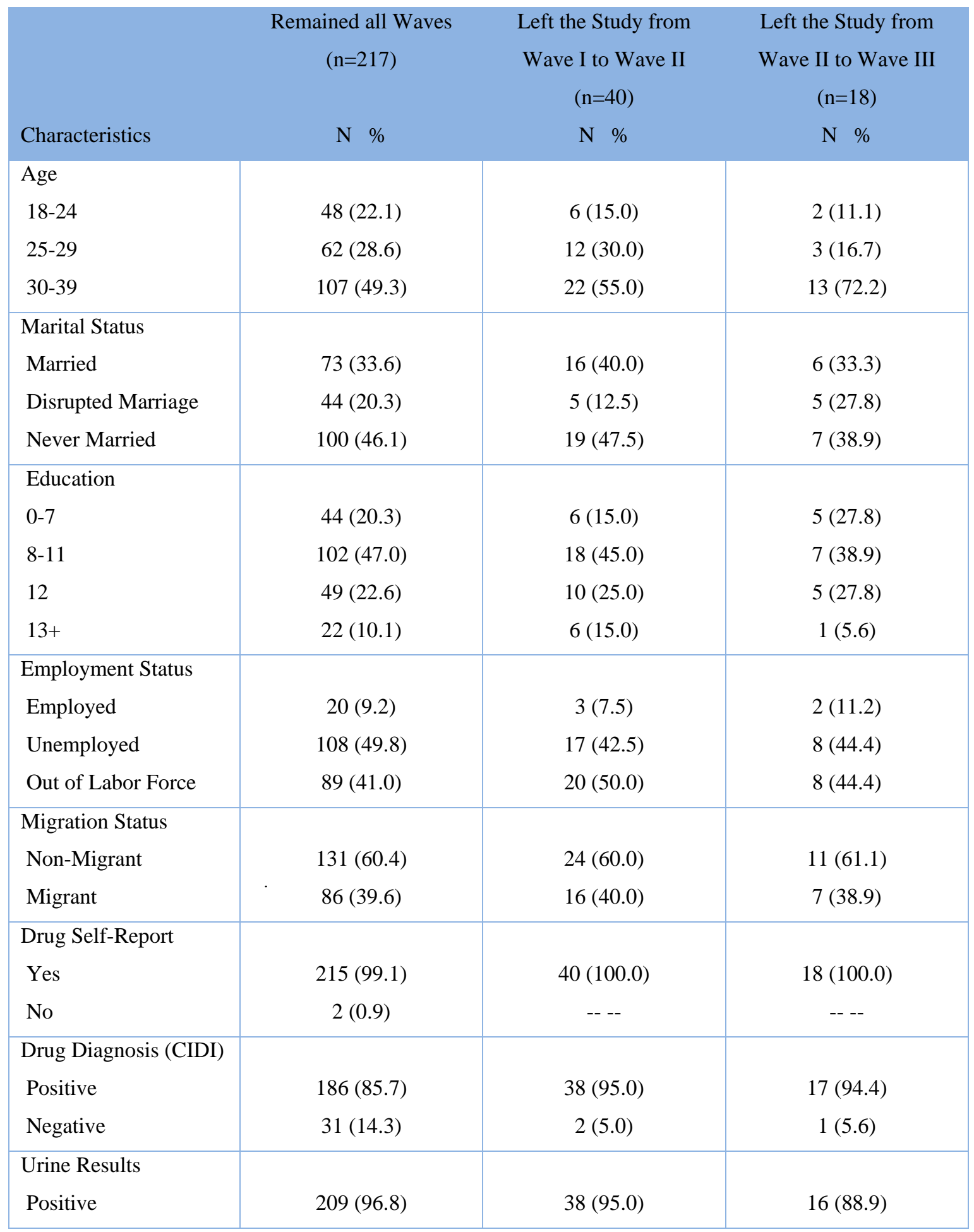




\begin{tabular}{|l|c|c|c|}
\hline Negative & $7(3.2)$ & $2(5.0)$ & $2(11.1)$ \\
\hline HIV $\S$ & & & \\
Positive & $49(23.0)$ & $14(36.8)$ & $7(41.2)$ \\
Negative & $164(77.0)$ & $24(63.2)$ & $10(58.8)$ \\
\hline STD's & & & $5(29.4)$ \\
Positive & $67(31.5)$ & $8(21.1)$ & $12(70.6)$ \\
Negative & $146(68.5)$ & $30(78.9)$ & $9(50.0)$ \\
\hline Prostitution & $96(44.2)$ & $22(55.0)$ & $9(50.0)$ \\
Yes & $121(55.7)$ & $18(45.0)$ & \\
No & & & \\
\hline
\end{tabular}

Note: $*$ p-value $<0.05$

$\S \mathrm{p}$-value $=0.06$

community and treatment in prison with $5.1 \%$. For the women receiving treatment during the study, the most frequent type was treatment in prison (4.5\%), a combination of detox and residential therapeutic community (4.5\%), detox $(3.3 \%)$, and methadone $(2.9 \%)$. For both, women receiving treatment before and during the study, residential therapeutic community and detox were the most utilized types. Type of treatment received between Wave I and Wave II, as well as between Wave II and Wave III are shown in Table 3. A combination of detox and therapeutic community treatment were the most frequent types for women between Waves I and II with 10 users (4.3\% of the total sample), followed by prison and detox, both with $3.8 \%$, and therapeutic community alone with $2.6 \%$. Between Waves II and III, the most utilized type was methadone with 5 women using it $(2.2 \%$ from the total sample), followed by residential therapeutic community and prison (4 women), both with $1.7 \%$, and detox with 2 persons treated. 
Table 3: Treatment Type Received During the Study by Waves

\begin{tabular}{|c|c|c|c|c|c|c|}
\hline & \multicolumn{3}{|c|}{$\begin{array}{l}\text { Between Waves I and II } \\
\qquad \mathrm{n}=235\end{array}$} & \multicolumn{3}{|c|}{$\begin{array}{l}\text { Between Waves II and III } \\
\qquad \mathrm{n}=229\end{array}$} \\
\hline & Freq & Valid\% & Cum $\%$ & Freq & Valid\% & Cum \% \\
\hline No Treatment & 187 & 79.6 & 79.6 & 211 & 92.1 & 92.1 \\
\hline Detox & 9 & 3.8 & 83.4 & 2 & .9 & 93.0 \\
\hline Methadone & 4 & 1.7 & 85.1 & 5 & 2.2 & 95.2 \\
\hline Residential Therapeutic Community (TC) & 6 & 2.6 & 87.7 & 4 & 1.7 & 96.9 \\
\hline Prison & 9 & 3.8 & 91.5 & 4 & 1.7 & 98.7 \\
\hline Detox + Methadone & 2 & .9 & 92.3 & 1 & .4 & 99.1 \\
\hline Detox + Residential TC & 10 & 4.3 & 96.6 & 1 & .4 & 99.6 \\
\hline Residential TC + Prison & 1 & .4 & 97.0 & & & \\
\hline Detox + Prison & 2 & .9 & 97.9 & 1 & .4 & 100 \\
\hline $\begin{array}{l}\text { Detox + Prison + Ambulatory Non- } \\
\text { Methadone }\end{array}$ & 1 & .4 & 98.3 & & & \\
\hline Detox + Ambulatory Non-Methadone & 2 & .9 & 99.1 & & & \\
\hline $\begin{array}{l}\text { Residential TC + Ambulatory Non- } \\
\text { Methadone }\end{array}$ & 1 & .4 & 99.6 & & & \\
\hline $\begin{array}{l}\text { Detox }+ \text { Residential TC }+ \text { Ambulatory } \\
\text { Non-Methadone }\end{array}$ & 1 & .4 & 100 & & & \\
\hline Total & 235 & 100 & & 229 & 100 & \\
\hline
\end{tabular}

Due to the importance of residential therapeutic community (RTC) type of treatment, a dichotomous dummy variable was created. Out of the 231 women who had treatment before the study, $142(51.6 \%)$ received at least one episode of RTC, whereas 59 women (21.5\%) received only non-residential. Between Waves I and II, out of the 48 participants who received treatment, 19 had at least one RTC, and 29 of them only non-residential. Between Waves II and III, a total of 13 women did not have RTC (5.7\%), and only 5 $(2.2 \%)$ received it. 
Table 4: Residential versus Other Type of Treatment

\begin{tabular}{|l|c|c|c|c|}
\hline & $\begin{array}{c}\text { At Least One } \\
\text { Episode of RTC }\end{array}$ & $\begin{array}{c}\text { Only Non- } \\
\text { Residential }\end{array}$ & $\begin{array}{c}\text { Received } \\
\text { Treatment }\end{array}$ & No Treatment \\
\hline $\begin{array}{l}\text { Treatment Before the } \\
\text { Study n=275 }\end{array}$ & $142(51.6 \%)$ & $59(21.5 \%)$ & $201(73.1 \%)$ & $74(26.9 \%)$ \\
\hline $\begin{array}{l}\text { Treatment Between } \\
\text { Wave I and II n=235 }\end{array}$ & $19(8.1 \%)$ & $29(12.3 \%)$ & $48(20.4 \%)$ & $187(79.6 \%)$ \\
\hline $\begin{array}{l}\text { Treatment Between } \\
\text { Wave II and III }=229\end{array}$ & $5(2.2 \%)$ & $13(5.7 \%)$ & $18(7.9 \%)$ & $212(92.1 \%)$ \\
\hline
\end{tabular}

Two logistic regressions models were used to examine the relationship between social capital and obtaining treatment. Several independent variables that were found with significant bivariate relation to the dependent variable drug treatment, as well as social capital measurements were also included in the final model. Covariates of treatment before the study include: children living with you; number of people in family composition; income from public assistance; receives social services; services from government financial assistance (ranging from $\$ 0$ to $\$ 761$ ); received help from WIC; received help from food stamps; number of medical visits during the last six months; total spent on drugs; history of severe sexual abuse; and, prostitution practice. For treatment received during the study, the covariates include: number of medical visits last 6 months (range 0 to 25); perception of physical health; and total spent in drugs. The best model for the dependent variable, received treatment before the study includes the following independent variables: received public assistance, number of medical visits during last 6 months, severe sexual abuse exposure, family composition, and the social capital measures. The best model for the dependent variable received treatment during the study includes the following independent variables: received treatment before the study, number of medical visits last six months, perception of physical health, total spent on drugs, and the social capital measures. Table 5 shows four independent variables significant in this model: two of them were negatively associated with receiving treatment before the study (receipt of public assistance, OR .996, 95\% CI .994-.999); and number of people in family composition (OR .813, 95\% CI .701.943). The other two significant variables were severe sexual abuse exposure (OR 2.841, 
95\% CI 1.315-6.136), and social capital subscale 3 in Wave I (OR 1.068, 95\% CIs 1.0111.128). Number of medical visits last 6 months, was marginally significant, and negative associations of receiving public assistance and the number of people in family composition were found. Social support from relatives and being exposed to severe sexual abuse also were associated. Only two variables overlap with treatment before and during the study: number of medical visits and total amount spent in drugs.

Table 5: Received Treatment Before the Study

\begin{tabular}{|c|c|c|c|c|c|c|}
\hline & & B & SE & $\operatorname{Exp}(\beta)$ & $95 \% \mathrm{Cl}$ & $r \operatorname{Exp}(\beta)$ \\
\hline & & & & & Lower & Upper \\
\hline Receive public as & & -.004 & .001 & $.996 * *$ & .994 & .999 \\
\hline Number of medic & ts last 6 months & .158 & .092 & $1.172 \S$ & .978 & 1.403 \\
\hline Total spent in dru & & .001 & .001 & 1.001 & 1.000 & 1.002 \\
\hline Severe sexual ab & posure & 1.044 & .393 & $2.841 * *$ & 1.315 & 6.136 \\
\hline Number of peopl & mily & -.207 & .076 & $.813 * *$ & .701 & .943 \\
\hline $\begin{array}{l}\text { Social capital sub } \\
\text { from friends) }\end{array}$ & 1 Wave I (social support & .026 & .026 & 1.026 & .975 & 1.081 \\
\hline $\begin{array}{l}\text { Social capital sub } \\
\text { cohesion) }\end{array}$ & 2 Wave I (neighborhood & .003 & .037 & 1.003 & .933 & 1.078 \\
\hline $\begin{array}{l}\text { Social capital sub } \\
\text { from relatives) }\end{array}$ & 3 Wave I (social support & .066 & .028 & $1.068^{*}$ & 1.011 & 1.128 \\
\hline Social capital iter & ave I (church participation) & .144 & .346 & 1.155 & .586 & 2.278 \\
\hline Constant & & .507 & .732 & 1.660 & & \\
\hline -2 Log likelihood: & $* \mathrm{p}<.05$ & & & & & \\
\hline Nagelkerke $\mathrm{R}^{2}$ & $* * \mathrm{p}<.01$ & & & & & \\
\hline Chi-square & $\begin{array}{ll}45.554 * * * & * * * p<.001 \\
& \& p=.085\end{array}$ & & & & & \\
\hline
\end{tabular}

Table 6 presents the results of receiving treatment during the study, which combines received treatment between Waves. The model shows two predictors of treatment receipt during the time the study was conducted (from May 1996 to October 2000): perception of physical health (OR 2.410, 95\% CI 1.071-5.420); and, total amount of money spent on drugs (OR 1.001, 95\% CI 1.000-1.002. 
Table 6: Received Treatment During the Study

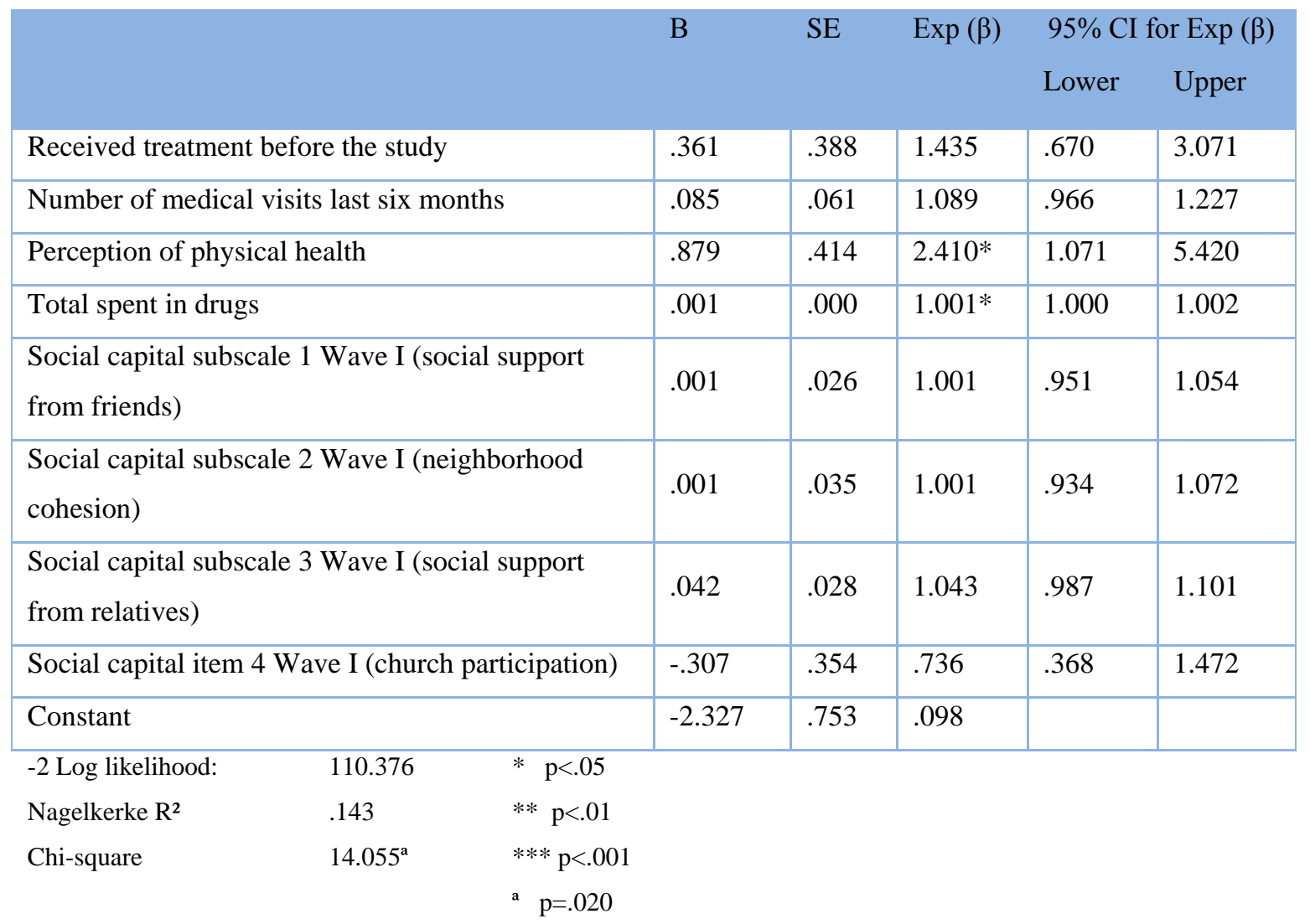

Social capital was not associated with receiving treatment during the study, and only social support from friends (subscale 3) was positively associated with receiving substance abuse treatment before the study with a $\mathrm{p}<.05$. Four Ordinary Least Square (OLS) regressions models were run to explore the predictors of social capital. Each OLS model corresponds to each social capital indicator as dependent variables. By using the baseline score of each subscale of social capital as a control variable in each model for Wave III measures of the dependent variables, these analyses provide a perspective of determinants of change in social capital. The covariates of the social capital scale in Wave III were drawn from baseline Wave I data including: employment status, total monthly income, education, fulltime job, receives social services, and home ownership. The model included scores of social capital scale in Wave I and the item, how many times you go to church?, which were found to have a bivariate correlation to social capital Wave III. After running several 
models, not significant variables were removed including education, full-time job, receives social services, and home ownership. The final model include: total monthly income from work and other activities, and employment status. Table 7 shows the predictors of social support from friends in Wave III (subscale 1 Wave III). The adjusted $\mathrm{R}^{2}$ for this model was .069. Two independent variables were found to be significant predictors of social support from friends: employment status negatively $(\mathrm{p}<.05)$, and social support from friends in Wave I $(\mathrm{p}<.01)$ with a positive association. Total monthly income was found to be marginally significant $(\mathrm{p}=.061)$ and had a negative relationship with the outcome variable.

Table 7: Predictors of Social Support From Friends by Wave III (subscale 1 Wave III)

\begin{tabular}{|c|c|c|c|c|}
\hline & B & SE & $\beta$ & $\mathrm{T}$ \\
\hline Constant & 4.761 & .914 & & 5.209 \\
\hline Social support from friends (subscale 1 Wave I) & .196 & .071 & .182 & $2.734 * *$ \\
\hline Total monthly income & .002 & .001 & .124 & $1.885 \S$ \\
\hline Employment status & 1.846 & .913 & .131 & $2.021^{*}$ \\
\hline Received treatment during the study & -.019 & 1.037 & -.001 & .985 \\
\hline \multicolumn{5}{|l|}{ Adjusted $\mathrm{R}^{2}: .069 * \mathrm{p}<.05$} \\
\hline \multirow[t]{3}{*}{$\mathrm{F}: 5.215^{* * *}$} & & & & \\
\hline & & & & \\
\hline & & & & \\
\hline
\end{tabular}

In terms of neighborhood cohesion as a dependent variable, two variables were significant predictors and a third was marginally significant (see Table 8). The neighborhood cohesion subscale had a positive relationship to the outcome, whereas employment status and total monthly income had a negative relationship with the outcome. Neighborhood cohesion subscale in Wave I was significant at the $\mathrm{p}<.001$ level, the employment status was significant at the $\mathrm{p}<.05$, and total monthly income at the $\mathrm{p}<.05$. The adjusted $\mathrm{R}^{2}$ for this model is .116. 
Table 8: Predictors of Neighborhood Cohesion by Wave III (subscale 2 Wave III)

\begin{tabular}{|c|c|c|c|c|}
\hline & B & SE & $\beta$ & $\mathrm{T}$ \\
\hline Constant & 10.395 & .933 & & 11.704 \\
\hline Neighborhood cohesion (subscale 2 Wave I) & .305 & .062 & .306 & $4.914^{* * *}$ \\
\hline Total monthly income & -.002 & .001 & -.126 & $-2.011 *$ \\
\hline Employment status & -1.254 & .575 & .136 & $-2.181 *$ \\
\hline Received treatment during the study & .107 & .658 & .010 & .870 \\
\hline \multicolumn{5}{|l|}{ Adjusted $\mathrm{R}^{2}: .116 * \mathrm{p}<.05$} \\
\hline 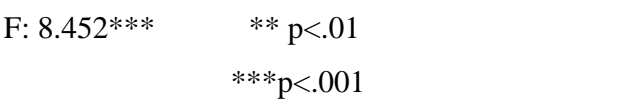 & & & & \\
\hline
\end{tabular}

Table 9 illustrates the predictors of social support from relatives, with an adjusted $\mathrm{R}^{2}$ of .154. In this model, the variables social support from relatives in Wave I $(p<.001)$, and employment status $(\mathrm{p}<.01)$, both had a positive association to the dependent variable. The rest of the variables had no statistical significance in predicting social support from relatives in Wave III.

Table 9: Predictors of Social Support from Relatives by Wave III (subscale 3 Wave III)

\begin{tabular}{|lllll|}
\hline & B & SE & $\beta$ & T \\
\hline Constant & 6.513 & 1.007 & & 6.467 \\
\hline Social Support from relatives (subscale 3 Wave I) & .361 & .061 & .360 & $5.876^{* * * *}$ \\
\hline Total monthly income & .000 & .001 & .029 & .472 \\
\hline Employment status & 2.240 & .734 & .184 & $3.054^{* *}$ \\
\hline Received treatment during the study & .723 & .844 & .053 & .392 \\
\hline \hline
\end{tabular}

$\begin{array}{ll}\text { Adjusted } \mathrm{R}^{2}: .154 & * \mathrm{p}<.05 \\ \mathrm{~F}: 11.377 * * * & * * \mathrm{p}<.01 \\ & * * * \mathrm{p}<.001\end{array}$

For the item 4 of the social capital measure (how often you go to church), two variables were significant: the frequency of church assistance in Wave I ( $p<.01)$, and total monthly income $(\mathrm{p}<.05)$. The first had a positive association, whereas the total monthly income 
variables had a negative relationship to the outcome. This model had an $\mathrm{R}^{2}$ of .047 (Table 10).

Table 10: Predictors of How Often You Go To Church? by Wave III (item 4 Wave III )

\begin{tabular}{|lllll|}
\hline & B & SE & $\beta$ & T \\
\hline Constant & 3.999 & .460 & & 8.690 \\
\hline How often you go to church? (item 4 social capital Wave I) & .221 & .078 & .188 & $2.837^{* *}$ \\
\hline Total monthly income & -.001 & .000 & -.131 & $-1.983^{*}$ \\
\hline Employment status & -.051 & .214 & -.016 & -.240 \\
\hline Received treatment during the study & -.043 & .243 & -.012 & .859 \\
\hline \hline Adjusted $\mathrm{R}^{2} .047 * \mathrm{p}<.05$ & & & & \\
F: $3.821^{* *} \quad * * \mathrm{p}<.01$ & & & & \\
$\quad * * * \mathrm{p}<.001$ & & & &
\end{tabular}

Receiving drug abuse treatment during the study did not predict social capital in any of its subscales. Employment status, and total monthly income were significant in the majority of the subscales but receipt of treatment was not even close to being significant in any of them.

\section{DISCUSSION}

Contrary to the proposed hypothesis that higher individual social capital would predict participation in one or more treatment programs, no association was found between social capital and obtaining drug abuse treatment neither before nor during the study. Getting treatment may be the case for other groups with higher socioeconomic status and higher levels of human capital, but not for the ones studied in this project. An important issue is related to the level of measurement of social capital. In this study, individual level social capital was utilized due to the lack of neighborhood level data. Community level social capital, based on aggregating individual perception of trust, reciprocity (Subramanian, Lochner \& Kawachi 2003), interracial/interclass relations, and membership to voluntary associations, and diversity of friendships (Brown \& Scheffler 2004) may have better explanatory power in elucidating the role of social capital in treatment. Particularly 
considering that health outcomes are a consequence of macro level processes (Pearce \& Smith 2003; Subramanian, Kawachi \& Kennedy 2001). Social capital appears not necessarily to be a protective factor among participants in the study, having negative consequences as suggested by previous studies on its properties (Muntaner \& Lynch 1999; Caughy, O’Campo \& Muntaner 2003). It seems reasonable to suggest that having less support from friends who are drug users may translate into better health outcomes including the reduction of drug use and drug related problems. In this particular group of drug using women in Puerto Rico, lower levels of social support from other drug using friends may act as a protective factor. It has been suggested that support from non-drug using friends is associated with better health behaviors and greater use of health services, whereas support from drug using friends is equivalent to not having support (Nyamathi et al 2000). An interesting finding of this study is that there is no overlap of variables related to receiving treatment prior to the study and predictors of treatment during the study, except for the number of medical visits during the last six months. Another finding suggests that the majority of the women obtained treatment before the study, $73.1 \%$, in comparison to women who received treatment during the study with $21.2 \%$. This last finding was interpreted by one of the interviewed experts, Colón, as:

\footnotetext{
Not strange, rather, very similar to what we have observed in our studies... there is more opportunity to enter treatment for men, approximately $25 \%$, and less opportunity for women with around $20 \%$ ". [He continued explaining that there is]: "Less availability of services that admitted women, and generally the services for women have conditions that are adverse to them... for instance, in residential programs women are not allowed to bring their children, and if they are not able to accommodate their children with other family or friends they cannot go to treatment... or in methadone programs, women who get pregnant are detoxified and discharged from the program.
}

Alegría agreed and added that the need for treatment services is greater than the current capacity of delivery:

The capacity is very small compared to the need... in fact there is very little detox, and now they are beginning to increase methadone treatment... in a study we conducted on the impact of managed 
care in mental health... we found no change... although one of the problems is the measure of selfreport drug use, that is why we had tested hair and urine of participants of the ICLDUS."[participants received detox because] "...they wanted to reduce their drug use -lowering the dosage of cocaine or heroin- because they were in a range of drug use that was problematic, and detox helped them to lower the dosage.

She also mentioned that more than $90 \%$ of women in prison have been arrested for problems associated to drug use, in comparison to about $76 \%$ of the men. She and her team could not identify the number of people receiving treatment in prison. She said that:

\footnotetext{
The majority of them received detox, which is not really treatment..." [if detox were to be removed] "We will not have any treatment reported... what we know is that women who enter a detox is because they are using a lot of drugs... realizing that if they do not go to detox they cannot keep with the amount of drugs they use... when women were asked why are you seeking for treatment? They response was not because they wanted to quit rather to lower the dosage.
}

The variables receive treatment before and receive treatment during the study have methodological differences that are necessary to clarify. Prior treatment is retrospective, whereas treatment receipt during the study is prospective. The independent variables associated to prior treatment are subsequent to the treatment episode and represent the consequences of receiving treatment before the study began, whereas independent variables associated to treatment during the study are predictors of the dependent variable because they are previous to the treatment episode. Variables associated with receiving drug abuse treatment before the study were receiving public assistance, severe sexual abuse exposure, number of people in family composition, and social support from relatives subscale in Wave I. Two variables had a negative association with drug treatment received before the study. These variables were receiving public assistance and the number of people in family composition. Severe sexual abuse exposure and social support from relatives were associated positively to treatment before the study. The fact that this was a retrospective analysis made the interpretation speculative, because there is no baseline data of receiving treatment before the study. There is only a relationship of association between the 
independent and dependent variables, in which the dependent variable occurred before the independent variables forming the baseline. Receiving treatment before the study was associated with receiving less public assistance, having less family members living at home, having a history of sexual abuse, and more medical visits during last six months. When the dependent variable was treatment received during the study, the predictors were perception of physical health and total spent in drugs. The findings indicate a connection between perception of physical health and the number of medical visits and receipt of drug abuse treatment. Although, there was no significant bivariate correlation between perception of physical health and the number of visits to their doctor during the previous six months, both were correlated with treatment use. Women who perceived themselves as having good health were more likely to receive drug abuse treatment in comparison to women with a perception of their health status as less than optimal. Also, women with visits to their physician which may be related to new practices of linking primary care practice to drug abuse treatment (Samet, Friedmann, \& Saitz 2001). The role of physicians' recognition of drug abuse and related problems and referral to drug abuse treatment appears to be important. According to Quiñones: "If the primary care physician is adequately trained, the person may be referred to the appropriate treatment for their addiction... this happens primarily with women of low-income". The other predictor of obtaining treatment during the study is the amount of money spent on drugs during the past month. Women who spent more of their economic resources on drugs were more likely to obtain treatment. Although, there is no literature indicating the relationship between the amounts of money spent on drugs and patterns of seeking drug abuse treatment, a possible interpretation is that they were tired of using a big part of their money in drugs. Apparently people do not have to "hit bottom" as the Alcoholics Anonymous and some other approaches suggests, rather it seems that people need to be tired of being drug users and spending a great deal of their money on it. It appears that women do not go to treatment for many reasons. Colón and Quiñones agreed that many women want to get drug abuse treatment but they may be afraid of losing their children or their home due to current policies that penalize drug users. In addition, the insufficient availability of treatment makes it difficult for them to get into one 
of the programs. In this study, it appears that women go to treatment not because they have higher levels of social capital, rather because they spent much of their economic resources on drug activities, and also because they perceived themselves as having good health. There is no theory on the role these factors have on treatment-seeking behavior. Some important differences exist between the arrangements of drug abuse treatment in Puerto Rico and the continental USA. Quiñones mentioned that there are two main differences. One is the lack of availability and access to treatment:

There are only 10 residential therapeutic community treatment centers available for women in Puerto Rico, whereas in cities such as Boston -I don't remember the number but I know there have many more."[The other difference is the limited continuum of care for low-income drug abusers] "In Boston, there are approximately 21 modalities in the continuum (of care) and here, in Puerto Rico, it is very limited.

Those differences need to be framed in the general system of provision of health care, in which, under the current managed care arrangements (cuidado dirigido), derived from the 1994 Health Reform, the public health system carves out treatment services. Although, there is no evidence of changes in the delivery of services before and after managed care (Alegría et al. 2001; 2001-02), at least this system is not equipped to attend to addiction and any other health conditions that the women may experience in the same location, which may constitute a barrier to access. Quiñones mentioned that:

There is not a treatment setting in which they may attend to the two problems (dual diagnosis)... [In addition to the limitations of treating two chronic conditions in the same setting] Because the system is not set to attend to people with chronic illnesses or with psychological issues at the same time as their drug addiction, this may constitute a barrier to treatment.

Other barriers to receiving treatment among low-income Puerto Rican women include issues related to housing, employment, and the reception of services. Colón mentioned that some variables acted very different among addicted populations compared to the rest of the population such as in the case of housing: 
If an addict has its own residency, this can be an obstacle to receiving treatment because he or she can't afford to keep it while in treatment... women are more likely to have their own place in comparison to men... for instance, in the case of men, we found that close to $50 \%$ of the adults addicts live with their parents, whereas in the case of women it is almost $0 \% \ldots$ If a woman has her own apartment in housing she could lose it if she wants to enter a residential treatment..." [In terms of employment] "A large portion of men with drug addiction tend to have employment in the informal sector (i.e. sale newspapers in a traffic light), which constitutes a barrier to treatment... if they enter treatment for a prolonged period of time, more than 3 or 4 days (i.e. therapeutic community), they lose their job because when he comes back someone will take his position... in formal employment this does not happen, because you may use your vacation or sick time..." [In the case of women] "There is a lot of prostitution... although I am not sure of the effects of prostitution in getting treatment." [In the case of receiving government assistance] "Some of the programs would operate in a positive way whereas others in a negative... some stimulate them to receive treatment... it would be important to investigate this situation in detail... there is another very serious issue facing women to obtain treatment is the risk of losing their children... she can be an addict and the Department of Family has not yet found out about her addiction, or nobody has reported her... if she gets into treatment the Department may visit her house to see if there is negligence or abuse... this can be a very important obstacle... but also, this may work on the contrary, when the Department knows of the addiction and pressure her to get into treatment as a condition not to remove her children.

According to Alegría, the low use of outpatient services among participants, in comparison to similar populations in the US, is due to the lack of available treatment. Another important element to consider is the low tolerance for people with drug abuse. There is more tolerance for people with alcohol abuse issues:

... a politician said 'if they use drugs they deserved to die.' We still having this moralist notion in Puerto Rico that people use drugs because they want... not as a problem of (public) health... in fact, historically, the resources were allocated to health problems affecting all the population and not to drug users... it was only after the appearance of HIV that groups were mobilized to set up services for infected people which in many cases were related to drug use... this create a certain degree of importance... there was no political will to established services... it was not until the wide spread 
news of HIV and drugs... in Puerto Rico the worst thing is to be drug user...particularly for women... institutions and family are harder with female users.

A number of predictors of social capital were found for each of its subscales. Receiving treatment during the study, however, did not predict social capital. For the subscale 1, social support from friends, the predictors included employment status and baseline social support from friends. In terms of employment status, women who were out of labor force by Wave I, had significantly lower levels of social support from friends in comparison to employed or unemployed participants. Being out of labor force may indicate that people render their efforts to obtaining a job, not having any hope in changing their employment status. Although, there is no literature on the relationship of employment and social capital, several studies associated the role of employment on health status. For instance, employment for substance abusers is correlated to better health outcomes (Zanis et al. 1994), and more social functioning (Room 1998). In this study, women who were employed experienced an increase in their social support from friends, which suggests higher social functioning among the employed. It is important to mention that work conditions may be related to drug abuse or relapse. For instance, one study found that jobs with high levels of physical demands and low levels of skill discretion increased the risks of drug abuse (Muntaner et al. 1995). Another study reported that adverse psychosocial work conditions were predictors of poor functional status (Cheng et al. 2002). The other predictor of social support from friends in Wave III was social support from friends in Wave I, which is self-explanatory. Women with more social support from their friends tended to keep their previous levels of social support from friends. For the subscale 2, neighborhood cohesion, the predictors were total monthly income, employment status and baseline neighborhood cohesion. In this case, women who were out of labor force had higher levels of perceived neighborhood cohesion. The neighborhood cohesion subscale included perception of belonging to the neighborhood, interaction with other neighbors, their wishes to continue living in the neighborhood, their feeling of being equal as other neighbors, and sense of community. Women who were out of the labor force showed more of these perceptions. This may suggest that higher levels of perceived neighborhood 
cohesion in low-income communities act as a coping mechanism. Although there was not a racial/ethnic group to compare with this study, literature suggests that these groups experience disproportionately higher levels of the social factors that adversely affect health and contribute to disparities in health among drug users (Galea \& Vlahov 2002). Living in a deprived neighborhood that lacks employment opportunities, and the dependence on scarce collective resources, had negative effects on health constituting a source of chronic stress (Stafford \& Marmot 2003; Steptoe \& Feldman 2001). Women out of the labor force are engaged in more drug use and related problems (Kidorf et al. 1998). Another predictor of neighborhood cohesion was monthly income, which was negatively associated. Women with less income were more likely to experience an increase in their perception of neighborhood cohesion. A possible explanation is that women receiving less income may tend to rely on sources of neighborhood support as a coping mechanism. The last predictor was neighborhood cohesion, which implied that women with higher scores in subscale 2 in Wave I experience an increase in their perceived levels of neighborhood cohesion by Wave III. For the subscale 3, social support from relatives, employment status and social support from relatives in Wave I were found to be predictors. As social support from friends (subscale 1) women who were employed or actively looking for a job were more likely to have higher levels of social support from relatives. Social support from relatives appears to be derived from an active participation in the labor market, as opposed to participants out of the labor force, which had less social support from their relatives. Being out of the labor force may result in a conflict within family members, resulting in disruption of family ties. The other predictor was social support from relatives in Wave I. Having higher levels of social support appeared to remain or increase over time when people are engaged in productive activities such as having a meaningful job. For the item 4 (how often you go to church?), the predictors were total monthly income and the item 4 in Wave I. Women with less monthly income were less likely to increase their frequency of church attendance, and inversely, women with more income were more likely to attend church more frequently. Participants with more church attendance at baseline were more likely to increase or keep their social participation in church. Employment status was a predictor of the 3 subscales of 
social capital; total monthly income predicted the neighborhood cohesion and frequency of church attendance; and, each subscale and the item were predictors to their correspondent outcome variable. That is, baseline social capital functioned as a predictor of social capital by Wave III; and, employment status and total monthly income were associated with social capital. Therefore, implementing programs that aim at increasing social capital alone may not be as effective as adapting macro level social and economic policies to enable stable employment and increase salaries, which may have a more positive effect on the lives of drug using women. No significant difference was found between the group who received treatment and the group who did not get treatment. However, the mean for subscale 1, social support from friends, appears to drop for people who received drug treatment. A possible explanation is that when people go through drug treatment they have less association with their drug associated friends, at least during the period of time the study was conducted. Social networks have an important influence on drug abuse rehabilitation and treatment-seeking behaviors; having fewer friends who use drugs results in better outcomes for treated and treatment-seeking individuals (Best et al. 2003). Both groups had a little less attendance to church, which may be explained by other factors not related to receiving or not receiving drug abuse treatment. In terms of social capital theory, the findings suggest that being involved in a drug treatment program does not affect individual level social capital. The increase in social functioning after receiving treatment was not reflected in the development of a more supportive environment that included individual social capital (trust, reciprocity, and membership), represented by the measures developed in this research. No significant difference between the group who received at least one time residential therapeutic community and the group who received only other type of treatment was found. The subscale 1, differences of social support from friends between Waves I and III, was found to be almost significant. This suggests that women who received other than residential therapeutic community type of treatment had less social support from their friends. It seems plausible to suggest that a more positive social network with friends may result in seeking and obtaining a more involved type of treatment such as residential therapeutic community. Although the results indicate a slight decrease in neighborhood 
cohesion and the social support from relatives for the group receiving at least one residential type treatment, neither type of treatment contributed significantly to changes in social capital. Colón mentioned that the type of treatment received might be influenced by other variables such as availability of treatments. Quiñones corroborated this when she reported the existence of only 10 available residential therapeutic community treatment centers for women in Puerto Rico. The theory of current treatment design is based on the hypothesis that treatment is responsible for a substantial part of the outcomes in terms of mortality, morbidity, functional status, health status and quality of life. Women receiving residential therapeutic community treatment experienced an increase in their social support from friends (although the association was marginally significant). This indicates that the benefits of this modality of treatment are only represented by this measure of individual social capital.

The set of findings seems to be are more consistent with the neo-materialist approach to social capital and indicates important limitations of the social support approach. Social capital may be better represented by the capacity of participant women to command the negotiation of scarce resources by their integration into social networks, as suggested by Portes (1998). Those social networks may facilitate women's access to the limited number of treatment programs. That is, women negotiate access to treatment through their capacity to mobilize their social networks in this deprived environment, and not necessarily through their social relations with family and friends and their social participation.

STUDY LIMITATIONS. This study represented an initial attempt to elucidate the two-way relationship between social capital and substance abuse treatment among a cohort of lowincome ethnic/racial women. Although a small sample, the ICLDUS data were very strong, considering that this is the first study of such proportion using well-validated tools, as well as physical and self-report measures of drug abuse. Although findings of the relationship between social capital and substance abuse treatment facilitated the identification of policy and program implementation interventions that may assist in reducing the problems 
associated with substance abuse among low-income women, as well as future research directions. In addition, a better understanding of the predictors of obtaining substance abuse treatment among low-income ethnic/racial women points was reached; and this in turn assists in pointing to strategies to increase treatment access for people in need. This research has a number of limitations including the generalizability of the results due to the relatively low number of participants who received treatment during the ICLDUS study, and the particularity of the Puerto Rican population living on the Island, which may not allow for extrapolating the findings to other similar communities on the continental USA. The group who received treatment and the one who did not are very similar. A larger sample is needed to account for variability. As the findings suggest, social capital changes over time but not in a systematic way, and the measures developed in this research cannot explain the variability. For instance, even with the closest measure of social capital (how often you go to church?) the sample required to account for the variation is 17,529 participants (considering a .80 power and .05 significance level). An important issue is that this study is framed in the particularities of the treatment delivery system in Puerto Rico. The particularities of drug abuse treatment in Puerto Rico, according to Colón, include:

Less availability of services and higher severity of addiction... both are closely related... less available services provoked an increase in the severity of the problem in comparison to the USA... if you look at practically all the indicators of drug use in Puerto Rico, they are much lower than in theUS(almost half)... if you look at the indicators of abuse, dependence, or misuse, they are in general much more severe.

[His take on this disparity is that] Puerto Rico, being a conservative society, constitutes a protector environment for initiation rates... but once the person initiates drug use, the environment tends to be less tolerant, which pushes the individual to a higher level of use... that is why we have those distributions: less use, but once using starts there is more severity.

Social capital may play a different role or may be defined in a different manner in the lives of women versus men. Gender influences many social phenomena so it is logical to assume that if the study also included males the results would vary. The definition and approaches 
to the measurement of social capital are still evolving and no single, empirically supported paradigm has been determined. The definition of the concept has continued to remain ambiguous. The relationship between the sources of social capital and the benefits derived from them remains conceptually unclear. The fact that this research consists of a secondary data analysis presents some limitations related to the information incorporated into the research. Qualitative interviews with some of the participant women and direct social observations of the neighborhoods were lacking to complement the survey responses.

POLICY IMPLICATIONS. The fact that higher levels of social capital did not predict treatment utilization suggests at least that the allocation of resources should not be aimed at increasing individual social capital, rather to provide more treatment programs. The lack of available treatment programs, according to Quiñones, means that when women finally go into a treatment program their health is much more deteriorated. Due to the fact that there are less available treatment programs adds to the severity of drug abuse and related health problems, more availability will contribute to improving the overall health of women in need of treatment. The interviewed researchers suggested that available treatment programs, under managed care arrangements, should integrate into the treatment program comorbid conditions often found with substance abuse. Dual diagnosis and chronic conditions should be treated and integrated into treatment programs. Also, creating systems in which primary care, mental health and substance abuse services are linked. In addition, increase outreach efforts with trained personnel, and intense case management to assist women in obtaining treatment and to coordinate services. This approach may reduce the severity of the problems associated with drug abuse and the overall improvement in the health status of low-income women. Another policy and practice issue is the implementation of mechanisms in government programs targeting this population that motivate women with substance abuse problems to obtain treatment. Receiving public assistance was found to be associated with obtaining treatment in this study. Government assistance, however, was associated both negatively and positively to getting treatment. Some programs may help women to get into a treatment facility, whereas others may 
penalize them for having a drug problem. Programs may act ambivalently, for instance the Department of Family may motivate women to get into treatment if they are involved with the family, or threaten with removing her children because she has a drug abuse problem. In this case, the Department should implement a mechanism that motivates women to ask them for help. Programs should increase the likelihood of getting into treatment and not serve as deterrents, including a component that eliminates penalization and stigma. Treatment utilization did not contribute to the increase of individual social capital; neither did attending to residential therapeutic community. Increasing levels of individual social capital in low-income communities may not have a positive outcome, as documented by other studies (Muntaner \& Lynch 1999; Caughy, O'Campo, \& Muntaner 2003; Veenstra 2000). If community level social capital has a more dynamic influence on health outcomes and treatment seeking patterns, the emphasis of policies should be directed towards eliminating sources that contribute to substance abuse and related problems such as deprivation of economic resources. In addition to promoting social policies that enable lowincome women to have a more productive and meaningful life, increasing access to resources and social benefits. Pilot studies exploring the role of implementing government program may assist in designing better approaches for women to receive treatment. It is also important to determine the mechanisms by which structural factors contribute to drug related problems. Exploring in depth how low-income Puerto Rican women recover and seek treatment would allow an understanding of these pathways and facilitate the design/implementation of better policy and program interventions for other similar population groups. 


\section{BIBLIOGRAPHICAL REFERENCES}

Akers, R., M. Kron, L. Lanza-Kaduce \& M. Radosevich, 1979, «Social learning and deviant behavior: A specific test of a general theory». American Social Review, n. 44, pp. 639-655.

Albizu-Garcia, C., M. Alegría, D. Freeman \& M. Vera, 2001, «Gender and Health Services Use for a Mental Health Problem». Social Science \& Medicine, v. 53, n. 7, pp. 865-878.

Alegría, M., 1996-2000. Inner City Latina Drug Use Study (ICLDUS). Universidad de Puerto Rico, Puerto Rico.

Alegría, M., T. McGire, M. Vera, G. Canino, L. Matías \& J. Calderon,2001, «Changes in access to mental health care among the poor and nonpoor: results from the health care reform in Puerto Rico». American Journal of Public Health, v. 91, n. 9, pp. 1431-1434.

Alegría, M., T. McGuire, M. Vera, G. Canino, D. Freeman, L. Matias, C. Albizu, H. Marín \& J. Calderon, 2001-2002, «The impact of managed care on the use of outpatient mental health and substance abuse services in Puerto Rico». Inquiry, v. 38, n. 4, pp. 381-395.

Alegría, M., M. Vera, G. Negrón, M. Burgos, C. Albizu, G. Canino, 2002, «Methodological and conceptual issues understanding female Hispanic drug users». In Drug Addiction Research and the Health of Women, Wetherington, C. \& Roman, A. (eds.), pp. 529-551. National Institute on Drug Abuse.

Alegría, M., M. Vera, P. Shrout, G. Canino, S. Lai, C. Albizu, H. Marin, M. Peña \& D. Rush, 2004, «Understanding hard-core drug use among urban Puerto Rican women in highrisk neighborhoods». Addictive Behaviors, v. 29, n. 4, pp. 643-664.

Alegría, M., 2004, Personal communication. 
Alegría, M., et al., unpublished, Consequences of drug use for urban City Latina women.

Amaro, H. \& A. de la Torre, 2002, «Public health needs and scientific opportunities in research on Latinas». American Journal of Public Health, v. 92, n. 4, pp. 525-529.

Ashley, O., M. Marsden \& T. Brady, 2003, «Effectiveness of substance abuse treatment programming for women: a review». American Journal of Drug \& Alcohol Abuse, v. 29, n. 1, pp. 19-53.

Bandura, A., 1969, Principles of Behavior Modification. Holt, Rinehart \& Winston, New York.

1977, Social Learning Theory. General Learning Press, New York.

1997, «Public health and civil society: Understanding and valuing the connection». Australian and New Zealand Journal of Public Health, v. 217, n. 7, pp. 673-675.

Berkman, L., 2000, «Social support, social networks, social cohesion and health». Social Work \& Health Care, v. 31, n. 2, pp. 3-14.

Berkman, L. \& T. Glass, 2000, «Social integration, social networks, social support and health». In Social Epidemiology, L. Berkman, \& I. Kawachi (eds.). Oxford University Press, New York.

Best, D., R. Hernando, M. Gossop, C. Sidwell \& J. Strang, 2003, «Getting by with a little help from your friends: the impact of peer networks on criminality in a cohort of treatmentseeking drug users». Addictive Behavior, v. 28, n. 3, pp. 597-603. 
Bolin, K., B. Lindgren, M. Lindstrom \& P. Nystedt, 2003, «Investments in social capitalimplications of social interactions for the production of health». Social Science and Medicine, v. 56, n. 12, pp. 2379-2390.

Bresnahan, K., B. Zuckerman, \& H. Cabral, 1992, «Psychosocial correlates of drug and heavy alcohol use among pregnant women at risk for drug use». Obstet Gynecol, v. 80, n. 6, pp. 976-980.

Brook, J., M. Whiteman, C. Nomura, A. Gordon, et al., 1988, «Personality, family, and ecological influences on adolescent drug use: A developmental analysis». Chemical Dependence \& Treatment, v. 1, n. 2, pp. 123-161.

Brook, J., D. Brook, A. Gordon, M. Whiteman \& P. Cohen, 1990, «The psychosocial etiology of adolescent drug use: a family interactional approach». Genet Soc Gen Psychol Monogr, v. 116, n. 2, pp. 111-267.

Brown, T. \& R. Scheffler, 2004, The Hazards of Being Unconnected: Community Social Capital, Individual Social Capital and Mental Health in the United States. Retrieved April, 2004, from the World Wide Web: http://www.icsbhs.org/presentations/brown.pdf.

Caughy, M., P. O'Campo \& C. Muntaner, 2003, «When being alone might be better: neighborhood poverty, social capital, and child mental health». Social Science \& Medicine, v. 57, n. 2, pp. 227-37.

Centers for Disease Control, CDC, 2007, «HIV/AIDS Surveillance Report: Cases of HIV Infection and AIDS in the United States and Dependent Areas, 2007». Retrieved March 2010. http://www.cdc.gov/hiv/topics/surveillance/basic.htm 
Cheng, Y., I. Kawachi, E. Coakley, J. Schwartz \& G. Colditz, 2002, «Association between psychosocial work characteristics and health functioning in American women: prospective study». British Journal of Medicine, v. 320, n. 7247, pp. 1432-1436.

Cloud, W. \& R. Granfield, 2001, «Natural recovery from substance dependency: Lessons for treatment providers». Journal of Social Work Practice in the Addictions, v. 1, n. 1, pp. 83-104.

Coburn, D., 2000, «Income inequality, social cohesion and the health status of populations: the role of neo-liberalism». Soc Sci Med, v. 51, n. 1, pp. 135-146.

Coleman, J., 1988, «Social capital in the creation of human capital». American Journal of Sociology, n. 94, pp. 95-120.

Colón, H., 2004, Personal communication.

Colón, H., G. Canino \& H. Sahai, 2001a, «Prevalence and correlates of DSM-IV substance use disorders in Puerto Rico». Boletín de la Asociación Médica de Puerto Rico, v. 93, ns. 112 , pp. 12-22.

Colón, H., R. Robles \& H. Sahai, 2001b, «The validity of drug use responses in a household survey in Puerto Rico: comparison of survey responses of cocaine and heroin use with hair tests». International Journal of Epidemiology, v. 30, n. 5, pp. 1042-1049.

2002, «The validity of drug use self-reports among hard core drug users in a household survey in Puerto Rico: comparison of survey responses of cocaine and heroin use with hair tests». Drug \& Alcohol Dependence, year 1, v. 67, n. 3, pp. 269-279. 
Cullen, M. \& H. Whiteford, 2001, «The interrelations of social capital with health and mental health». Commonwealthof Australia: National Mental Health Strategy, Discussion Paper. Retrieved, from the World Wide Web: http://www.health.gov.au/hsdd/ mentalhe/pdf/inter.pdf

Galea, S. \& D. Vlahov, 2002, «Social determinants and the health of drug users: socioeconomic status, homelessness, and incarceration». Public Health Reports, v. 117 (Suppl. 1), pp. S135-145.

Godoy, R., W. Leonard, V. Reyes-García, V. Vadez, T. Huanca, J. Bauchet, M. Ma. Miodosky, R. Olvera, K. Patel, J. St. John \& O. Zapata Rios, 2007, «On the measure of income and the economic unimportance of social capital: Evidence from a native Amazonian society of farmers and foragers». Journal of Anthropological Research, v. 63, pp. $239-260$.

Holtgrave, D. \& R. Crosby, 2003, «Social capital, poverty, and income inequality as predictors of gonorrhoea, syphilis, chlamydia and AIDS case rates in the United States». Sexualy Transmited Infections, v. 79, n. 1, pp. 62-64.

Kandel, D., L. Warner \& R. Kessler, 2003, «The epidemiology of substance use and dependece among women». In Drug Addiction Research and the Health of Women, edited by Wetherington, C., \& Roman, A., pp. 105-130. National Institute on Drug Abuse.

Kawachi, I., 1997, «Long live community. Social capital as public health». The American Prospect, v. 8, n. 35.

1999, «Social capital and community effects on population and individual health». Annals of the New York Academy of Sciences, v. 896. 
Kawachi, I. \& L. Berkman, 2000, «Social Cohesion, Social Capital, and Health». In Social Epidemiology, edited by I. Kawachi, \& Berkman, L., pp. 174-190. Oxford University Press, New York.

2001, «Social ties and mental health». Journal of Urban Health (Journal of urban health: bulletin of the New York Academy of Medicine), v. 8, n. 3, pp. 458-467.

Kawachi, I., B. Kennedy, K. Lochner \& D. Prothrow-Stith, 1997, «Social capital, income inequality, and mortality». American Journal of Public Health, v. 87, n. 9, pp. 1491-1498.

Kawachi, I., B. Kennedy, \& R. Glass, 1997, «Health and social cohesion: why care about income inequality?». BMJ, v. 314, n. 7086, pp. 1037-1040.

1999, «Social capital and self-rated health: a contextual analysis». American Journal of Public Health, v. 89, n. 8, pp. 1187-1193.

Kawachi, I., B .Kennedy \& R. Wilkinson, 1999, «Crime: social disorganization and relative deprivation». Social Science \& Medicine, v. 48, n. 6, pp. 719-731.

Kawachi, I., B. Kennedy, V. Gupta \& D. Prothrow-Stith, 1999, «Women's status and the health of women and men: a view from the States». Social Science \& Medicine, v. 48, n. 1, pp. 21-32.

Keating, D., 2000, «Social capital and developmental health: Making the connection». Journal of Developmental and Behavioral Pediatrics, v. 21, n. 1, pp. $50-52$.

Kidorf, M., J. Hollander, V. King \& R. Brooner, 1998, «Increasing employment of opioid dependent outpatients: an intensive behavioral intervention». Drug \& Alcohol Dependance, v. 50, n. 1, pp. 73-80. 
Lasser, K., D. Himmelstein, S. Woolhandler, D. McCormick \& D. Bor, 2002, «Do minorities in the United States receive fewer mental health services than whites?». International Journal of Health Services, v. 32, n. 3, pp. 567-578.

Lin, N., X. Ye et al., 1999, «Social support and depressed mood: a structural analysis». Journal of Health and Social Behavior, n. 40, pp. 344-359.

Lindstrom, M., B. Hansen, P. Ostergren \& G. Berglund, 2000, «Socio-economic differences in smoking cessation: the role of social participation». Scandinavian Journal of Public Health, v. 28, n. 3, pp. 200-208.

Lindstrom, M., J. Merlo \& P. Ostergren, 2003, «Social capital and sense of insecurity in the neighborhood: a population-based multilevel analysis in Malmo, Sweden». Social Science \& Medicine, v. 56, n. 5, pp. 1111-1120.

Lovell, A., 2002, «Risking risk: the influence of types of capital and social networks on the injection practices of drug users». Social Science \& Medicine, v. 55, n. 5, pp. 803-821.

Loury, G., 1992, «The Economics of Discrimination: Getting to the Core of the Problem». Harvard Journal of African American Public Policy, v. 1, pp. 91-110.

Mardsen, M., 1999, «Alcohol and Drug Services Study Phase I Report Series: Results form a National Survey of Facilities Directors». Client Populations in Substance Abuse Treatment Facilities. Presentation.

McCarty, D., Y. Caspi, L. Panas, M. Krakow \& D. Mulligan, 2000, «Detoxification centers: who's in the revolving door?». Journal of Behavioral Health Services Research, v. 27 , n. 3, pp. 245-256. 
McLellan, A. \& J. McKay, 1998, Appendix D, «The Treatment of Addiction: What Can Research Offer Practice?». In, Bridging the Gap Between Practice and Research: Forging Partnerships with Community-Based Drug and Alcohol Treatment, edited by S. Lamb, Greenlick, M., \& McCarty, D., pp. 147-185. Institute of Medicine, National Academy Press, Washington, DC.

McLellan, A., G. Woody et al., 1997, «Evaluating the effectiveness of addiction treatments: Reasonable expectation, appropriate comparisons». In Treating Drug Abusers Effectively, edited by J. Egerston, Fox, D., \& Lechner, A., pp. 7-40. Blackwell.

Morral, A., McCaffrey, D., \& Iguchi, M., 2000, «Hardcore drug users claim to be occasional users: drug use frequency underreporting». Drug Alcohol Depend, v.57, n.3, pp. 193-202.

Mulia, N., 2002, «Ironies in the pursuit of well-being: The perspectives of low-income, substance-using women on service institutions». Contemporary Drug Problems, v. 29, n. 4, pp. 711-748.

Muntaner, C., J. Anthony, R. Crum \& W. Eaton, 1995, «Psychosocial dimensions of work and the risk of drug dependence among adults». American Journal of Epidemiology, v. 142, n. 2, pp. 183-190.

Muntaner, C. \& J. Lynch, 1999, «Income inequality, social cohesion, and class relations: a critique of Wilkinson's neo-Durkheimian research program». International Journal of Health Services, v. 29, n. 1, pp. 59-81. 
Muntaner, C., J. Lynch, M. Hillemeier, J. Lee, R. David, J. Benach \& C. Borrell, 2002, «Economic inequality, working-class power, social capital, and cause-specific mortality in wealthy countries». International Journal of Health Services, v. 32, n. 3, pp. 629-656.

Nyamathi, A., B. Leake, C. Keenan \& L. Gelberg, 2000, «Type of social support among homeless women: its impact on psychosocial resources, health and health behaviors, and use of health services». Nursing Research, v. 49, n. 6, pp. 318-326.

Nyamathi, P. \& R. Vásquez, 1988, «Impact of poverty, homelessness, and drugs». Hispanic Journal of Behavioral Sciences, v. 11, n. 4, pp. 299-314.

Pearce, N. \& G. Smith, 2003, «Is social capital the key to inequalities in health?». American Journal of Public Health, v. 93, n. 1, pp. 122-129.

Pearlin, L., E. Menaghan, M. Lieberman \& J. Mullan, 1981, «The stress process». Journal of Health \& Social Behavior, v. 22, n. 231, pp. 331-356.

Pescosolido, B., E. Wright, M. Alegría \& M. Vera, 1998, «Social networks and patterns of use among the poor with mental health problems in Puerto Rico». Medical Care, v. 36, n. 7, pp. 1057-1072.

Portes, A., 1998, «Social capital: Its origins and applications in modern sociology». Annual Review of Sociology, n. 24, pp. 1-24.

Putnam, R., 1993, Making Democracy Work. Princeton University Press, Princeton, New York.

1995, «Bowling alone: America's declining social capital». Journal of Democracy, v. 6, n. 1, pp. 65-87. 
2000, Bowling alone: The collapse and revival of american community. Simon \& Schuster, New York.

Quiñones, E., 2004, Personal communication.

Randolph, W., C. Stroup-Benham, S. Black \& K. Markides, 1998, «Alcohol Use Among Cuban-Americans, Mexican-Americans, and Puerto Ricans». Alcohol Health and Research World, v. 22, n. 4, pp. 265-269.

Reiff-Ross, E. \& H. Adams, 1977-1978, «Is this program a revolving door? Admissions and readmissions to a women's detox unit». Alcohol Health \& Research World, v. 2, n. 2, pp. 2-7 Winter

Reyes, J., R. Robles, H. Colón, T. Matos, H. Sahai \& D .Freeman, 1993, «Human inmunodeficiency virus infection and risk behaviors among injection drug users in four Puerto Rican communities». Health Sciences Journal, v. 12, n. 1, pp. 19-25.

Room, J., 1998, «Work and identity in substance abuse recovery». Journal of Substance Abuse Treatment, v. 15, n. 1, pp. 65-74.

Rosenheck, R., J. Morrissey, J. Lam, M. Calloway, M. Stolar, M. Johnsen, F. Randolph, M. lasinsky\& H. Goldman, 2001, «Service delivery and community: social capital, service systems integration, and outcomes among homeless persons with severe mental illness». Health Services Research, v. 36, n. 4, pp. 691-710.

Ruiz, P., \& Langrod, J., 1997, «Hipanic Americans». In Lowinson, J. Ruiz, P., Milman, R., \& Langrod, J., (Coords), Substance Abuse: A Comprehensive Textbook, $3^{\text {nd }}$ Ed., Baltimore, MD: Williams \& Wilkins. 
Samet, J., P. Friedmann \& R. Saitz, 2001, «Benefits of linking primary medical care and substance abuse services: patient, provider, and societal perspectives». Archives of Internal Medicine., v. 161, n. 1, pp. 85-91.

SAMSHA, 2008, «Results from the 2008 National Survey on Drug Use and Health: National Findings. Electronic resource retrieved March 2010». In http://oas.samhsa.gov/NSDUH/ 2k8NSDUH/2k8results.cfm\#2.7

Singer, M., 1999, «Why do Puerto Rican drug users inject so often?». Anthropology \& Medicine, v. 6, n. 1, pp. 31-58.

Stafford, M. \& M. Marmot, 2003, «Neighborhood deprivation and health: does it affect us all equally?». International Journal of Epidemiology, v. 32, n. 3, pp. 357-366.

StatSoft, Inc., 2004, Electronic Statistics Textbook. StatSoft Inc.Tulsa, OK. Retrieved, 2004, from the World Wide Web: StasSoft.

In http://www.statsoft.com/textbook/stathome.html

Steptoe, A. \& P. Feldman, 2001, «Neighborhood problems as sources of chronic stress: development of a measure of neighborhood problems, and associations with socioeconomic status and health». Annals of Behavioral Medicine, v. 23, n. 3, pp. 177-185.

Subramanian, S., I. Kawachi \& B. Kennedy, 2001, «Does the state you live in make a difference? Multilevel analysis of self-rated health in the US». Social Science \& Medicine, v. 53, n. 1, pp. 9-19. 
Subramanian, S., K. Lochner \& I. Kawachi, 2003, «Neighborhood differences in social capital: a compositional artifact or a contextual construct?». Health Place, v. 9, n. 1, pp. 3344.

Szreter, S. \& M. Woollcock, 2002, «Health by association? Social capital, social theory and the political economy of public health». Unpublished manuscript.

Tabachnick, B. \& L. Fidell, 1996, Using Multivariate Statistics (3rd ed.). Harper Collins, New York.

Veenstra, G., 2000, «Social capital, SES and health: an individual-level analysis». Social Science \& Medicine, v. 50, n. 5, pp. 619-629.

Vera, M., M. Alegría, D. Freeman, R. Robles, B. Pescosolido \& M.Peña, 1998, «Help seeking for mental health care among poor Puerto Ricans: problem recognition, service use, and type of provider». Medical Care, v. 36, n. 7, pp. 1047-1056.

Weisner, C. \& L. Schmidt, 2001, «Rethinking Access to Alcohol Treatment». In Recent Developments in Alcoholism. Vol 15. Services Research in the Era of Managed Care, Galanter, M. (ed.). Kluwer Academic/Plenum Publishers, New York.

Weitzman, E. \& I. Kawachi, 2000, «Giving means receiving: the protective effect of social capital on binge drinking on college campuses». American Journal of Public Health, v. 90 n. 12, pp. 1936-1939.

Wilkinson, R., 1999, «Income inequality, social cohesion, and health: clarifying the theory-a reply to Muntaner and Lynch». International Journal of Health Services, v. 29, n. 3, pp. 525-543. 
Woolcock, M., 1998, «Social Capital and Economic Development: Towards a Theoretical Synthesis and Policy Framework». Theory and Society, n. 27, pp. 151-208.

Woolcock, M. \& D. Narayan, 2002, «Capital Social: Implicaciones para la Teoría, la Investigación y las Políticas sobre Desarrollo». The World Bank Group. In http://poverty.worldbank.org/library/view/13030, Retrieved June 26, 2003.

World Bank Group, The, 2002, «How social capital is measured?». The World Bank. In http://www.worldbank.org/ poverty/scapital/SChowmeas1.htm, Retrieved June 26, 2003.

Zanis, D., D. Metzger \& A. McLellan, 1994, «Factors associated with employment among methadone patients». Journal of Substance Abuse Treatment, v. 11, n. 5, pp. 443-447.

Zuckerman, M., 1990, «Some dubious premises in research and theory on racial differences: Scientific, social, and ethical issues». American Psychologist, v.45, pp. 12971303.

Fecha de recepción: 21 de noviembre de 2009.

Fecha de aceptación: 30 de marzo de 2010. 